\title{
Mitochondrial DNA sequence variation in Finnish patients with matrilineal diabetes mellitus
}

\author{
Heidi K Soini ${ }^{1,2}$, Jukka S Moilanen ${ }^{3}$, Saara Finnila ${ }^{1}$ and Kari Majamaa ${ }^{1,2^{*}}$
}

\begin{abstract}
Background: The genetic background of type 2 diabetes is complex involving contribution by both nuclear and mitochondrial genes. There is an excess of maternal inheritance in patients with type 2 diabetes and, furthermore, diabetes is a common symptom in patients with mutations in mitochondrial DNA (mtDNA). Polymorphisms in mtDNA have been reported to act as risk factors in several complex diseases.

Findings: We examined the nucleotide variation in complete mtDNA sequences of 64 Finnish patients with matrilineal diabetes. We used conformation sensitive gel electrophoresis and sequencing to detect sequence variation. We analysed the pathogenic potential of nonsynonymous variants detected in the sequences and examined the role of the m.16189 T>C variant. Controls consisted of non-diabetic subjects ascertained in the same population. The frequency of mtDNA haplogroup $\vee$ was 3-fold higher in patients with diabetes. Patients harboured many nonsynonymous mtDNA substitutions that were predicted to be possibly or probably damaging.

Furthermore, a novel m.13762 T>G in MTND5 leading to p.Ser476Ala and several rare mtDNA variants were found. Haplogroup H1b harbouring m.16189 T > C and m.3010 G > A was found to be more frequent in patients with diabetes than in controls.
\end{abstract}

Conclusions: Mildly deleterious nonsynonymous mtDNA variants and rare population-specific haplotypes constitute genetic risk factors for maternally inherited diabetes.

Keywords: Mitochondrial DNA, diabetes, Mitochondrial DNA haplogroups, m.16189 T>C, Maternal inheritance

\section{Background}

Mitochondria play a key role in metabolism, heat production and apoptosis and contribute to aging and formation of reactive oxygen species (ROS) [1,2]. Above all, mitochondrial oxidative phosphorylation (OXPHOS) produces adenosine triphosphate (ATP) that is the energy form driving cellular processes. Both nuclear genome and mitochondrial DNA (mtDNA) code for the subunits of the respiratory chain complexes that catalyse the reactions of OXPHOS. Maternally inherited mtDNA consists of 16569 base pairs and codes for 13 proteins of the respiratory chain, while the remaining more than 70 subunits are encoded by the nuclear genome.

\footnotetext{
* Correspondence: kari.majamaa@oulu.fi

'Institute of Clinical Medicine, Department of Neurology, University of Oulu, P.O. Box 5000, Fl-90014, Oulu, Finland

${ }^{2}$ Clinical Research Center, Oulu University Hospital, University of Oulu, P.O.

Box 5000, Fl-90014, Oulu, Finland

Full list of author information is available at the end of the article
}

Furthermore, mtDNA encodes 2 ribosomal RNAs and 22 tRNAs required for mitochondrial protein synthesis.

MtDNA is more prone to mutations than nuclear DNA leading to variation that can be used as a tool in population genetics. Certain polymorphisms mark branch points in the phylogenetic tree of human mtDNA and define population-specific haplogroups. Europeans belong to mtDNA haplogroups $\mathrm{H}, \mathrm{V}, \mathrm{U}, \mathrm{K}, \mathrm{T}, \mathrm{J}, \mathrm{I}, \mathrm{W}, \mathrm{X}$ and $\mathrm{Z}$ [3]. Certain mtDNA haplogroups have been associated with susceptibility to various diseases but also with beneficial traits like longevity [4]. It has been postulated that certain mtDNA polymorphisms either decrease or increase the patency of the mitochondrial respiratory chain and the production of harmful ROS. Furthermore, some mildly harmful polymorphism can bring forth subtle changes in translation, replication or production of regulatory elements of mtDNA [4]. Supramolecular assembly of mitochondrial respiratory chain complexes have been suggested to create a dynamic supercomplex. Amino acid

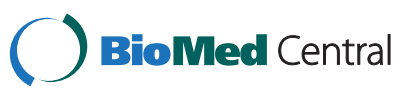


variation in subunits of complexes can have minor effects on the stability and assembly of the supercomplexes and may lead to impaired function of OXPHOS or increased ROS production [5,6].

Non-neutral patterns have been found in human mtDNA indicating that slightly deleterious mutations may be present in the population [7]. According to the neutral theory of molecular evolution, variation at the molecular level is due to the interaction between genetic drift and mutation, rather than being actively maintained by selection. Selection against mildly deleterious mtDNA mutations suggests that increased sequence variation could be a risk factor for complex diseases such as type 2 diabetes $[8,9]$. It has been proposed that recent bottleneck events can lead to the over-representation of minor mtDNA alleles in population and to the emergence of population-specific risk factors for diabetes [10].

Insulin-dependent type 1 and non-insulin dependent type 2 are the two main types of diabetes. Type 2 diabetes has an excess of maternal transmission and can be inherited through multiple maternal generations [11]. Mitochondrial diabetes constitutes the third type of diabetes. It accounts for $1 \%$ of all diabetes cases and is often accompanied by hearing impairment and other multi-organ symptoms typical for mitochondrial diseases. Mitochondrial diabetes is most often caused by the m.3243A > G mutation in MTTL [11-13].

The $\mathrm{m} .16189 \mathrm{~T}>\mathrm{C}$ polymorphism near the terminationassociated segment in the non-coding region of mtDNA creates an uninterrupted cytosine tract. The tract varies in length between five and 13 consecutive cytosines, the wild type genome containing nine cytosines with an intervening thymine in position m.16189 after the fifth cytosine. The m.16189 $\mathrm{T}>\mathrm{C}$ polymorphism diminishes the rate of mtDNA replication and causes a lower mtDNA copy number and a disadvantage in metabolic efficiency [14]. It has been speculated that m.16189 T acts as a brake for replication slippage or facilitates the whole process of replication. The m.16189 $\mathrm{T}>\mathrm{C}$ polymorphism has been linked with maternally inherited thinness [15], thinness at birth [16] and increased body mass index [17], and increased frequency of type 2 diabetes in the UK [18] and in Asia [19,20].

In this study we have attempted to identify mtDNA polymorphisms or their combinations that could increase the risk of maternally inherited diabetes. For this purpose, we determined complete mtDNA sequences in 64 Finnish patients with maternally inherited diabetes and compared them to complete mtDNA sequences in 192 population controls.

Subjects and Samples

Patients were identified from the records of 40 out of 42 local-authority health care units in Northern Finland. The discharge diagnoses and the diabetes register of two hospitals were reviewed. The selected patients had started insulin treatment for diabetes between the ages of 20 and 45 years and had maternal first- or seconddegree relatives with diabetes, hearing loss or epilepsy. A total of 175 patients were identified, 111 of them reported at least one first-degree maternal relative with diabetes. We received 82 blood samples.

We calculated a crude proportion of affected maternal relatives for each patient using $\mathrm{N}_{\text {affected }} / \mathrm{N}_{\text {total }}$ [21] after exclusion of the probands. We then selected 64 patients with the highest calculated crude proportion of maternal relatives. The mean crude proportion for the selected patients was 0.30 (standard deviation 0.19; median 0.25; range 0.077 - 1). Restriction fragment analysis was used to verify the absence of $\mathrm{m} .3243 \mathrm{~A}>\mathrm{G}$ and $\mathrm{m} .8344 \mathrm{~A}>\mathrm{G}$ in the selected samples.

Population controls consisted of 480 healthy Finnish Red Cross blood donors from Northern Finland. It was required that the donor and his or her mother were born in the same region, did not have diabetes, sensorineural hearing impairment or any neurological ailments. MtDNA haplogroups have been determined in all the 480 controls [3], the hypervariable segment I in the Dloop has been sequenced in 403 controls [22] and the entire mtDNA sequence has been determined in 192 controls [3]. The ethics committee of the University of Oulu and the Finnish Red Cross have approved the study protocol. All participants signed a written informed consent for participation in the study, all participants were adults.

\section{Methods}

\section{Conformation sensitive gel electrophoresis (CSGE)}

Total DNA was extracted from blood using the QIAmp Blood Kit (Qiagen, Hilden, Germany). MtDNA haplogroups were determined by restriction fragment analysis and Conformation sensitive gel electrophoresis (CSGE) was performed as described previously [23-25]. MtDNA coding region spanning the nucleotides m.577-m.16090 was amplified in 63 partially overlapping fragments. PCR fragments were amplified in a total volume of 30 ? in 30 cycles through denaturation at $94{ }^{\circ} \mathrm{C}$ for $1 \mathrm{~min}$, annealing at a primer-specific temperature and extension at $72{ }^{\circ} \mathrm{C}$ for $1 \mathrm{~min}$ and a final extension for $10 \mathrm{~min}$. A touchdown-PCR protocol was used in parallel yielding similar results. The mean size of the amplified fragments was $354 \mathrm{bp}$. Small volume (3-10 ?l) of the PCR product was used for heteroduplex formation. Each amplified fragment was mixed with a reference sample and denatured at $95{ }^{\circ} \mathrm{C}$ for $5 \mathrm{~min}$ and annealed at $68{ }^{\circ} \mathrm{C}$ for $30 \mathrm{~min}$ for heteroduplex formation. Samples were electrophoresed using $15 \%$ polyacrylamide gel overnight at a constant voltage of $400 \mathrm{~V}$ in room temperature. After electrophoresis the gel was stained in 
150 ?g/l of ethidium bromide for $5 \mathrm{~min}$ and destained in water. Finally, the gel was transferred to ultraviolet transilluminator and photographed (Grab-IT Annotating Grabber 2.04.7; UVP).

\section{Sequencing}

PCR fragments that differed in mobility in CSGE were sequenced (ABI PRISM тм 377 Sequencer using DYEnamic ET Terminator Cycle Sequencing Kit; Amersham Pharmacia Biotech Inc., Buckinghamshire, U.K.) after purification with exonuclease I and shrimp alkaline phosphatase [26]. The primers for sequencing were the same as those used for the amplification of the 63 CSGE fragments. The D-loop spanning nucleotides m.15975 m.725 was sequenced directly.

\section{Analysis of substitutions}

Sequences were compared to the revised Cambridge reference sequence [GenBank:NC_012920] [27] and to mtDNA sequences available in the GiiB-JST mtSNP database http://mtsnp.tmig.or.jp/mtsnp/index_e.shtml [28], mtDB Human Mitochondrial Genome database http://www.mtdb.igp.uu.se [29] and Mitomap http:// www.mitomap.org [30] accessed in October 2011. All variants were also compared to our 192 populationspecific controls [3]. Novel substitutions were confirmed by restriction fragment length polymorphism-method (RFLP) or sequencing in both directions at least twice from different PCR products. Previously reported pathogenic mutations were identified according to Mitomap. Base conservation in tRNA genes was determined using Mamit tRNA: Compilation of Mammalian mitochondrial tRNA genes http://mamit-tRNA.u-strasbg.fr [31] and conservation of other mtDNA-encoded genes using the GiiB-JST mtSAP evaluation http://mtsnp.tmig.or.jp/cgi$\mathrm{bin} / \mathrm{mtsnp} /$ specAlign/ctrlSpecAlignE.cgi [28].

PolyPhen-2 version 2.1.0 [32] was used for prediction of functional effects of nonsynonymous mutations on subunit proteins http://genetics.bwh.harvard.edu/pph2/. For each mutation PolyPhen-2 calculates a naïve Bayes posterior probability that this mutation is damaging. Mutations are then classified as benign if the calculated probability is less than $50 \%$, possibly damaging if the probability is greater than $50 \%$ and probably damaging if the probability is greater than $90 \%$. HumDiv-model was used, because it is recommended for rare alleles in complex diseases and for mildly deleterious alleles [32]. The m.7444 G>A variant in haplogroup $\mathrm{V}$ creates a stop codon and, in consequence, could not be analyzed. PredictProtein was used to predict the secondary structure of subunits harbouring the variant amino acids identified among the patients [33]. Fisher's exact twotailed test was used to compare haplogroup frequencies, mutation frequencies and m.16189 $\mathrm{T}>\mathrm{C}$ genotype frequencies. Phylogenetic networks of mtDNA sequences were based on the median algorithm [34].

\section{Findings}

Frequency of mtDNA haplogroups

Haplogroup V was three times more common in patients with maternally inherited diabetes than in the population controls ( $p=0.0066$ for difference, Table 1). Subhaplogroup V8, defined by m.13350A $>$ G and m.14016G $>A$, was found at a frequency of $7.7 \%$ among the patients and $2.6 \%$ among the controls $(p=0.13$ for difference), whereas the frequency of subhaplogroup V1a was $3.1 \%$ in patients with diabetes and $6.2 \%$ in the controls ( $p=0.53$ for difference) (Figure 1). Interestingly, we discovered one patient belonging to haplogroup R1a, which is rare in the Finnish population.

\section{MtDNA variation in patients with maternally inherited diabetes mellitus}

A total of 209 coding region variants (Figure 2) and 83 D-loop variants (Figure 3) were found among patients with diabetes. Two of the variants were novel including the synonymous m.11266C $>\mathrm{T}$ transition in MTND4 and the nonsynonymous $\mathrm{m} .13762 \mathrm{~T}>\mathrm{G}$ transversion in MTND5 leading to p.Ser476Ala. Seven nonsynonymous variants were predicted to be possibly or probably damaging by PolyPhen-2 analysis (Table 2).

Three previously reported pathogenic nonsynonymous mutations were found, including m.4659G $>\mathrm{A}$ in MTND2

Table 1 Frequencies of mtDNA haplogroups among 64 patients with maternally inherited diabetes and $\mathbf{4 8 0}$ controls

\begin{tabular}{|c|c|c|c|c|c|}
\hline \multirow[b]{2}{*}{ Haplogroup } & \multicolumn{2}{|l|}{ DM } & \multicolumn{2}{|c|}{ Controls $^{1}$} & \multirow[b]{2}{*}{$p$-value } \\
\hline & $(\mathrm{N})$ & $(\%)$ & $(\mathrm{N})$ & (\%) & \\
\hline $\mathrm{H}$ & 23 & 35.9 & 188 & 39.1 & NS \\
\hline U & 15 & 23.4 & 134 & 27.9 & NS \\
\hline V & 10 & 15.6 & 27 & 5.6 & $0.0066^{*}$ \\
\hline $\mathrm{T}$ & 5 & 7.8 & 12 & 2.5 & NS \\
\hline 1 & 3 & 4.6 & 15 & 3.1 & NS \\
\hline K & 3 & 4.6 & 12 & 2.5 & NS \\
\hline W & 2 & 3.1 & 46 & 9.5 & NS \\
\hline$J$ & 2 & 3.1 & 26 & 5.4 & NS \\
\hline Z & 0 & 0 & 10 & 2.0 & NS \\
\hline$x$ & 0 & 0 & 7 & 1.4 & NS \\
\hline Other ${ }^{2}$ & 1 & 1.5 & 3 & 0.6 & NS \\
\hline
\end{tabular}

${ }^{1}$ The controls are those from [3].

${ }^{2}$ One patient with diabetes belonged to haplogroup $\mathrm{R}$.

*The frequency of haplogroup $V$ differed from that of the population controls ( $p=0.0066$, Fisher's exact two-tailed test, no adjustments were made for multiple comparisons). 


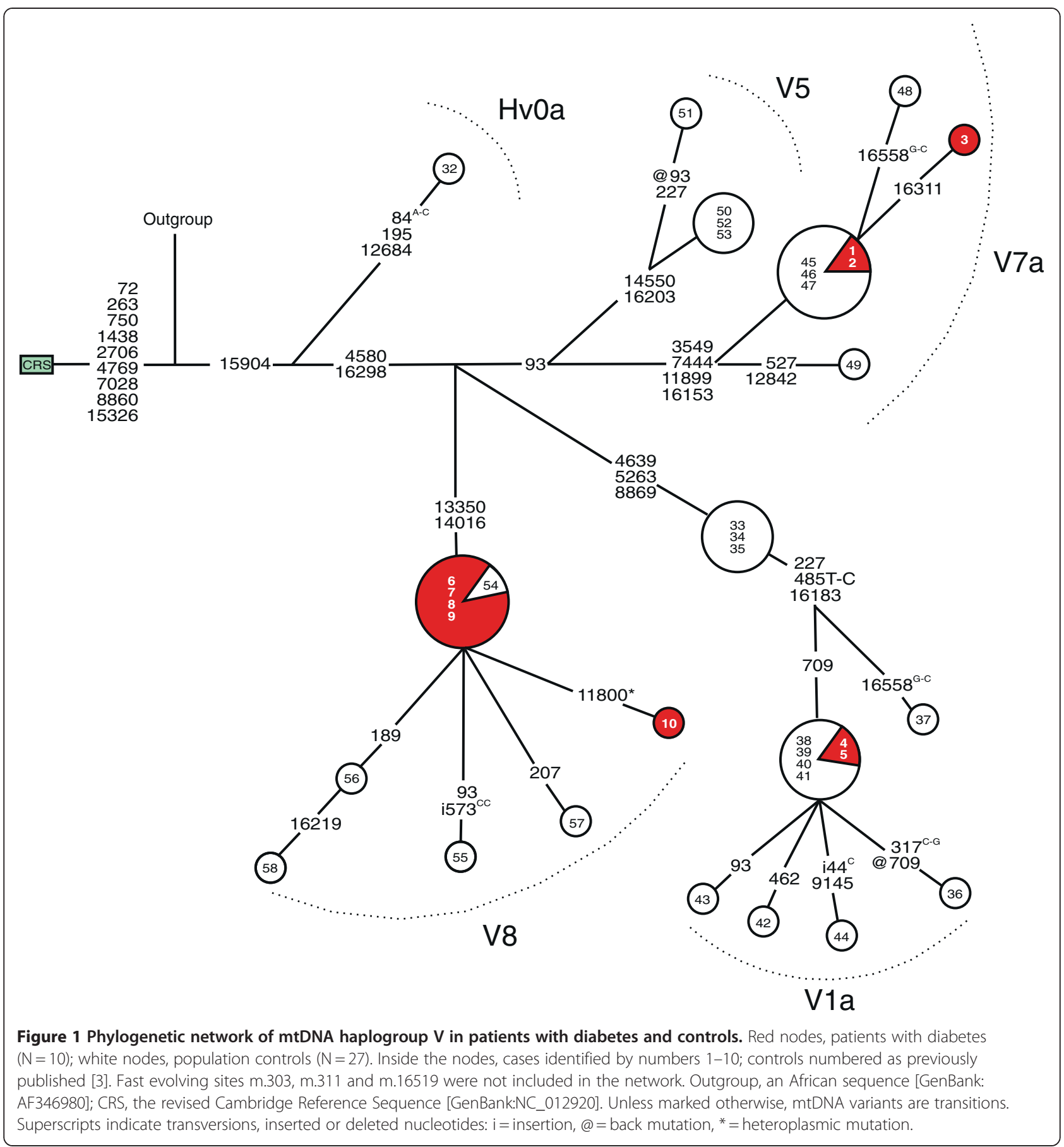

creating p.Ala64Thr in patient 19 [35], m.6480G $>$ A MTCO1 creating p.Val193Ile in patient 17 [36] and m.6489C $>$ A in MTCO1 creating p.Leu196lle in patients 59, 60 and 61 [37]. The m.4659G $>$ A mutation has been reported to contribute to Parkinson's disease, m.6480G $>\mathrm{A}$ has been linked to prostate cancer and $\mathrm{m} .6489 \mathrm{C}>\mathrm{A}$ to epilepsia partialis continua. However, all three variants were predicted to be benign in PolyPhen-2 analysis.

\section{MtDNA variants in tRNA encoding genes}

We discovered 13 substitutions in genes encoding tRNAs among the patients (Figure 2). The variants were most abundant in $M T T T$ encoding tRNA $^{\text {Thr }}$, where four polymorphisms were found including $\mathrm{m} .15904 \mathrm{C}>\mathrm{T}$ associated with haplogroup V, m.15907A $>$ G associated with subhaplogroup U2, m.15924A $>$ G that occurs in several haplogroups [38] and m.15928G $>$ A associated with haplogroup T. Heteroplasmic m.593T $>C$ was 


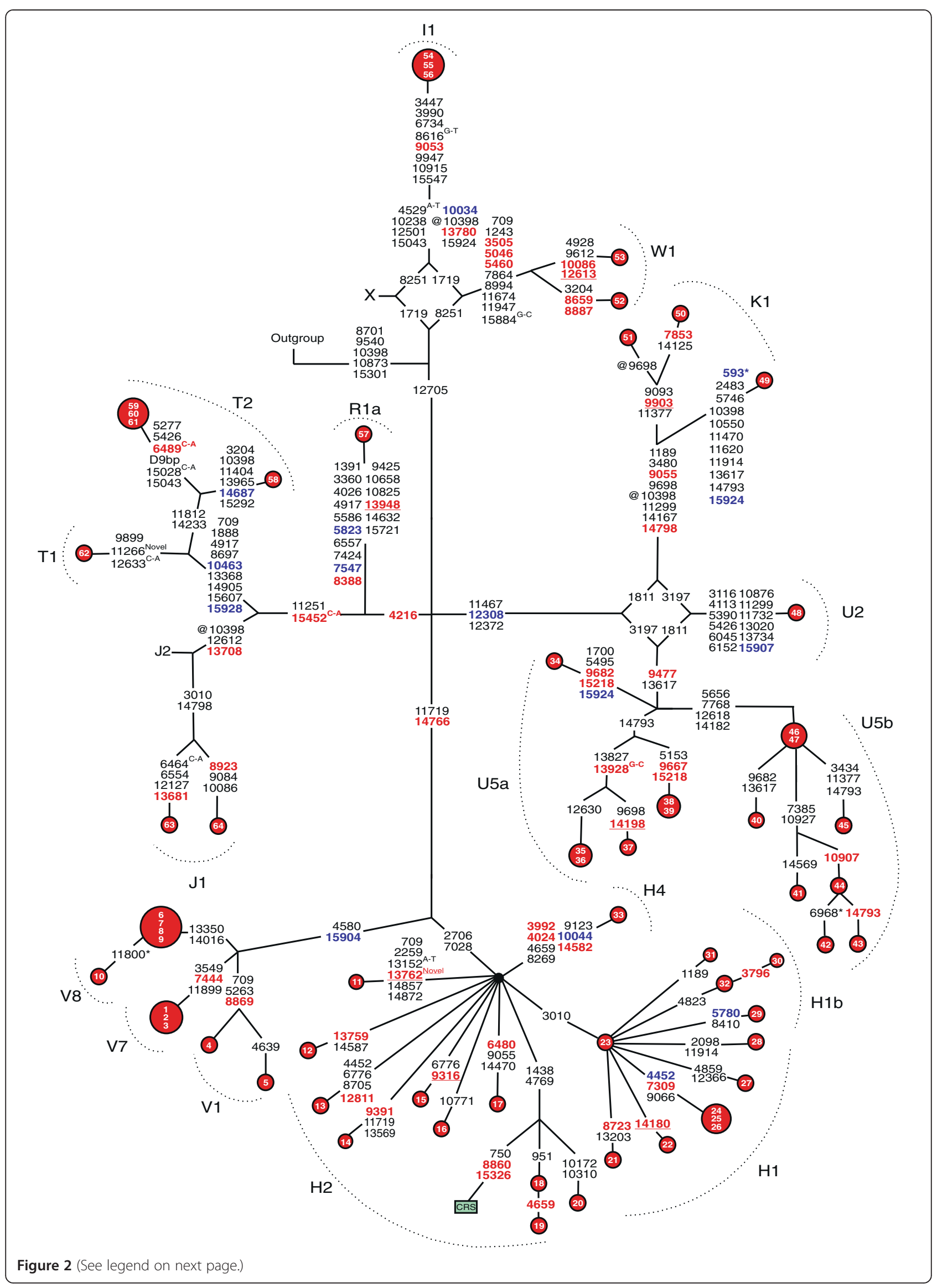


(See figure on previous page.)

Figure 2 Phylogenetic network based on the coding sequence of mtDNA from 64 patients with matrilineal diabetes. Inside the nodes, cases identified by numbers. Fast evolving sites m.303, m.311 and m.16519 were not included in the network. Outgroup, an African sequence [GenBank:AF346980]; CRS, the revised Cambridge Reference Sequence [GenBank:NC_012920]. Superscripts indicate transversions, novel variants and inserted or deleted nucleotides: i = insertion, D= deletion, @= back mutation, * = heteroplasmic mutation. D9bp, deletion spanning between the positions m.8281 and m.8289. Nonsynonymous substitutions are shown in red font, the tRNA variants in blue font. Underlined

nonsynonymous variants were deemed to be possibly or probably damaging in PolyPhen-2 analysis.

found in MTTF encoding tRNA ${ }^{\text {Phe }}$ in patient 49. Two mutations with previously reported disease associations were discovered in MTTC encoding tRNA ${ }^{\text {Cys }}$. Patient 29 belonging to subhaplogroup H1b harboured m.5780G $>$ A that has been found in a patient with sensorineural hearing impairment [39] and patient 57 belonging to subhaplogroup R1a harboured $\mathrm{m} .5823 \mathrm{~A}>\mathrm{G}$ that has been found in a patient with motor neuron disease and temporal lobe epilepsy [40]. The remaining six substitutions in genes encoding tRNAs included $\mathrm{m} .7547 \mathrm{~T}>\mathrm{C}$ in MTTD, m.10034T $>\mathrm{C}$ and $\mathrm{m} .10044 \mathrm{~A}>\mathrm{G}$ in $M T T G$, m.10463T $>C$ in MTTR, m.12308A $>\mathrm{G}$ in $M T T L 2$ and $\mathrm{m} .14687 \mathrm{~A}>\mathrm{G}$ in MTTE.

\section{m.16189T $>C$ polymorphism in matrilineal diabetes mellitus patients}

The frequency of $\mathrm{m} .16189 \mathrm{~T}>\mathrm{C}$ or the sequence of the cytosine tract surrounding this nucleotide did not differ between patients with diabetes and the controls (Table 3). Interestingly, phylogenetic analysis of the sequences harbouring $\mathrm{m} .16189 \mathrm{~T}>\mathrm{C}$ revealed four patients but no population controls belonging to subhaplogroup $\mathrm{H} 1 \mathrm{~b}$ ( $p=0.0038$ for difference; Figure 4$)$. We then searched for similar sequences among the 1865 complete and 839 coding region mtDNA sequences deposited in the mtDB database and found 30 sequences that harboured m.16189T $>$ C and m.3010G $>$ A. Only three of them [GenBank:AY195775, GenBank:AY738975, GenBank: AY738982] belonged to subhaplogroup H1b, while the remaining sequences belonged to subhaplogroup $\mathrm{H} 1 \mathrm{f}$ or to haplogroup J or D.

\section{Discussion}

Haplogroup V, more specifically subhaplogroup V8, was more common among patients with maternally inherited diabetes than among population controls in Northern Finland. Interestingly, haplogroup $\mathrm{V}$ has recently been reported to increase the risk of renal failure in patients with type 2 diabetes and haplogroup cluster $\mathrm{HV}$ has been associated with retinopathy in these patients [8]. Unfortunately, no data on diabetes complications was available for our patients.

Haplogroup V is common amongst the Saami people of Northern Scandinavia and North-Western Russia. About $40 \%$ of the Finnish Saami belongs to haplogroup V $[22,35,36]$. Certain mtDNA haplotypes considered to be Saami specific are found in the Finnish population suggesting a genetic admixture, which appears to be more pronounced in northern Finland. For example, the frequency of haplogroup $\mathrm{V}$ is $3 \%$ in northern Finland, but only $1 \%$ in Central Finland [22]. In the present study, patients and controls were ascertained from the same geographic area in order to minimise the bias caused by patients and controls originating from different populations.

One patient with diabetes belonged to haplogroup R1a, which is uncommon in Finland. In Europe, it occurs in the Kurdish population, Russia, Poland and the Caucasus area [37]. Our patient also harboured m.5823A $>\mathrm{G}$ in MTTC encoding tRNA ${ }^{\text {Cys }}$. The $\mathrm{m} .5823 \mathrm{~A}>\mathrm{G}$ variant has previously been reported in a haplogroup R1 sequence originating from India [37] and as a pathogenic mutation in a Caucasian patient with motor neuron disease and temporal lobe epilepsy. Unfortunately, no information about the haplogroup of this patient is available [38]. Our patient with diabetes and with $\mathrm{m} .5823 \mathrm{~A}>\mathrm{G}$ had reported first-degree relatives with diabetes, dementia, hearing loss or tremor.

The m.5823A $>\mathrm{G}$ mutation is located in the amino acid acceptor stem of tRNA ${ }^{\text {Cys }}$ and alters a nonconserved base. The mutation was homoplasmic both in our patient and in the two previous cases. In the amino acid acceptor stem of $\mathrm{tRNA}^{\mathrm{Cys}}$ three polymorphisms and no pathogenic mutations have been found. In general, mutations in the tRNA acceptor stem affect the stability of the tRNA molecule and several of such mutations have been reported to cause mitochondrial disease phenotypes $[39,40]$. The nonconserved nature of the mutated nucleotide and the homoplasmic state suggests that $\mathrm{m} .5823 \mathrm{~A}>\mathrm{G}$ is a polymorphism associated with haplogroup $\mathrm{R}$ rather than a disease-causing mutation.

We discovered the homoplasmic m.5780 G>A. A mutation in MTTC in a patient with first- and second degree relatives with diabetes and a first-degree relative with dementia. The same mutation, but in a heteroplasmic state has previously been found in a Finnish patient with sensorineural hearing impairment [41]. Both patients belonged to subhaplogroup H1b. The frequency of this subhaplogroup was $3.1 \%$ in the present patients, but subhaplogroup H1b was absent in the 192 controls. In MTTCC loop of the tRNA, five polymorphisms and six mutations with disease associations have been 


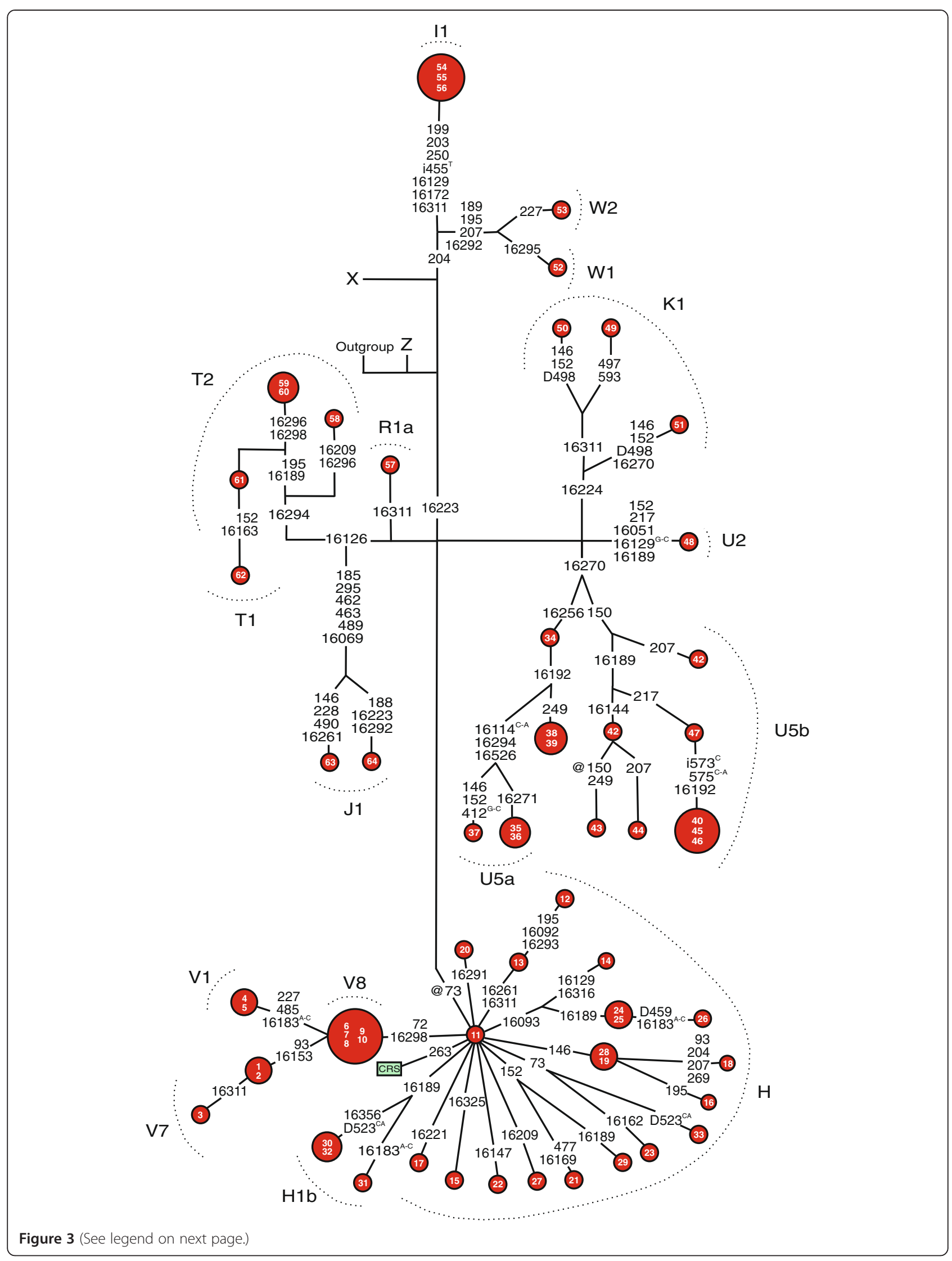


(See figure on previous page.)

Figure 3 Phylogenetic network based on the mtDNA D-loop sequences from 64 patients with matrilineal diabetes. The fast evolving site $\mathrm{m} .16519$ and the variants in the C-tract between the positions m.303-315 were not included in the network.The fast evolving site $\mathrm{m} .16519$ and the variants in the C-tract between the positions m.303-315 were not included in the network. Outgroup, an African sequence [GenBank: AF346980]; CRS, the revised Cambridge Reference Sequence [GenBank:NC_012920]. Unless marked otherwise, the polymorphic variants are transitions. Superscripts indicate transversions, inserted or deleted nucleotides and novel variants: i=insertion, D=deletion, @=back mutation.

reported. Four of the mutations are associated with sensorineural hearing impairment or deafness, one with progressive dystonia and one with mitochondrial encephalopathy [31]. The nucleotide in position m.5780 codes for an invariant conserved cytosine located in the TCys molecule. The present patient with diabetes and the previous patient with sensorineural hearing impairment shared identical mtDNA coding region sequences with the variants $\mathrm{m} .5780 \mathrm{G}>\mathrm{A}$ and $\mathrm{m} .8410 \mathrm{C}>\mathrm{T}$ suggesting that $\mathrm{m} .5780 \mathrm{G}>\mathrm{A}$ is a rare polymorphism in subhaplogroup H1b.

PolyPhen-2 analysis of the nonsynonymous mtDNA variants suggested seven possibly or probably damaging mutations (Table 2). The variants m.13948 $\mathrm{C}>\mathrm{T}$, m.14198 G > A, m.12613 G > A and m.14180 T > C had the highest probabilities predicting that these mutations are damaging. The m.13948 $\mathrm{C}>\mathrm{T}$ variant in MTND5 leading to p.Pro538Ser had a probability of $99.5 \%$, which makes it most probably a deleterious missense mutation.

We discovered two novel mtDNA variants. One was synonymous m.11266 $\mathrm{C}>\mathrm{T}$ and the other was nonsynonymous m.13762 $\mathrm{T}>\mathrm{C}$ in MTND5 leading to p.Ser476Ala. PolyPhen-2 analysis predicted that $\mathrm{m} .13762 \mathrm{~T}>\mathrm{C}$ is possibly damaging, although the site is not particularly conserved (Table 2). PredictProtein analysis predicted that this amino acid is located in a loop structure. These analyses suggested that m.13762 $\mathrm{T}>\mathrm{C}$ is probably a benign variant.

Three mutations with previously reported disease associations were found in our patients but not in the controls. The three mutations included m.4659 G>A leading to p.Ala64Thr [42], m.6480 G $>$ A leading to p.Val193Ile [43] and m.6489 C $>$ A leading to p.Leu196Ile [44]. These mutations were classified as benign in PolyPhen-2 analysis. Three sequences harbouring m.4659 G>A were detected in the mtDB database. These sequences belonged to haplogroups J, D and L, respectively, while our patient belonged to subhaplogroup $\mathrm{H} 2$ indicating that m.4659 G>A has arisen in multiple haplogroups. PolyPhen-2 analysis and phylogenetic comparison suggested that $\mathrm{m} .4659 \mathrm{G}>\mathrm{A}$ is a homoplasic polymorphism. The m.6480 $\mathrm{G}>\mathrm{A}$ variant was detected in the mtDB database in six samples belonging to haplogroups I, T2b, HV, L2, L3 and R31. Our patient with m.6480 G > A belonged to haplogroup $\mathrm{H}$. These findings suggest that m.6480 G>A is a homoplasic polymorphism. Three of our patients with diabetes and five sequences in the mtDB database harboured m.6489 C $>$ A. All eight sequences belonged to subhaplogroup T2 confirming that m.6489 $\mathrm{C}>\mathrm{A}$ is a polymorphism associated with this subhaplogroup [45].

We did not find differences in the frequency of m.16189 $\mathrm{T}>\mathrm{C}$ between patients and controls, or in the variation of the polycytosine tract surrounding this position (Table 4). The m.16189 $\mathrm{T}>\mathrm{C}$ variant has been linked to type 2 diabetes in Asians [19,20] and biochemical studies have revealed that the increased length of the cytosine tract is associated with a lower mtDNA copy number [14]. Furthermore, m.16189 T $>C$ has been associated with reduced ponderal index at birth and reduced birth weight, but not with diabetes status $[46,47]$.

Table 2 Possibly or probably damaging nonsynonymous mtDNA variants predicted by PolyPhen-2

\begin{tabular}{|c|c|c|c|c|c|}
\hline Variant & Gene & Protein change & Probability (\%) $^{1}$ & mtDB hits $^{2}(\mathrm{~N})$ & Family history \\
\hline $\mathrm{m} .13762 \mathrm{~T}>\mathrm{G}$ & MTND5 & p.Ser476Ala & 50.2 & - & $\mathrm{DM}, \mathrm{DEM}, \mathrm{HL}$ \\
\hline $\mathrm{m} .9316 \mathrm{~T}>\mathrm{C}$ & MTCO3 & p.Phe37Ser & 74.7 & 1 & $\mathrm{DM}$ \\
\hline $\mathrm{m} .9903 \mathrm{~T}>\mathrm{C}$ & MTATP6 & p.Phe233Leu & 75.6 & 1 & $\mathrm{DM}, \mathrm{T}$ \\
\hline m.14180 T > C & MTND6 & p.Tyr165Cys & 90.5 & 18 & DM, HL DEM \\
\hline m.12613 G>A & MTND5 & p.Ala93Thr & 97.2 & 4 & DM \\
\hline m.14198 G>A & MTND6 & p.Thr159Met & 98.4 & 2 & $\mathrm{DM}$ \\
\hline m.13948 C>T & MTND5 & p.Pro538Ser & 99.4 & 2 & $\mathrm{DM}, \mathrm{DEM}, \mathrm{T}$ \\
\hline
\end{tabular}

${ }^{1}$ Probability indicates the probability of the variant being damaging as estimated by PolyPhen-2. Probabilities $>50 \%$ are classified as possibly damaging and probabilities $>90 \%$ are classified as probably damaging.

${ }^{2}$ Number of sequences harbouring the variant among 1865 complete mtDNA sequences and 839 coding region sequences at http://www.mtdb.igp.uu.se/ $\mathrm{DM}$, diabetes mellitus; DEM, dementia; $\mathrm{HL}$, hearing loss; $\mathrm{T}$, tremor. 


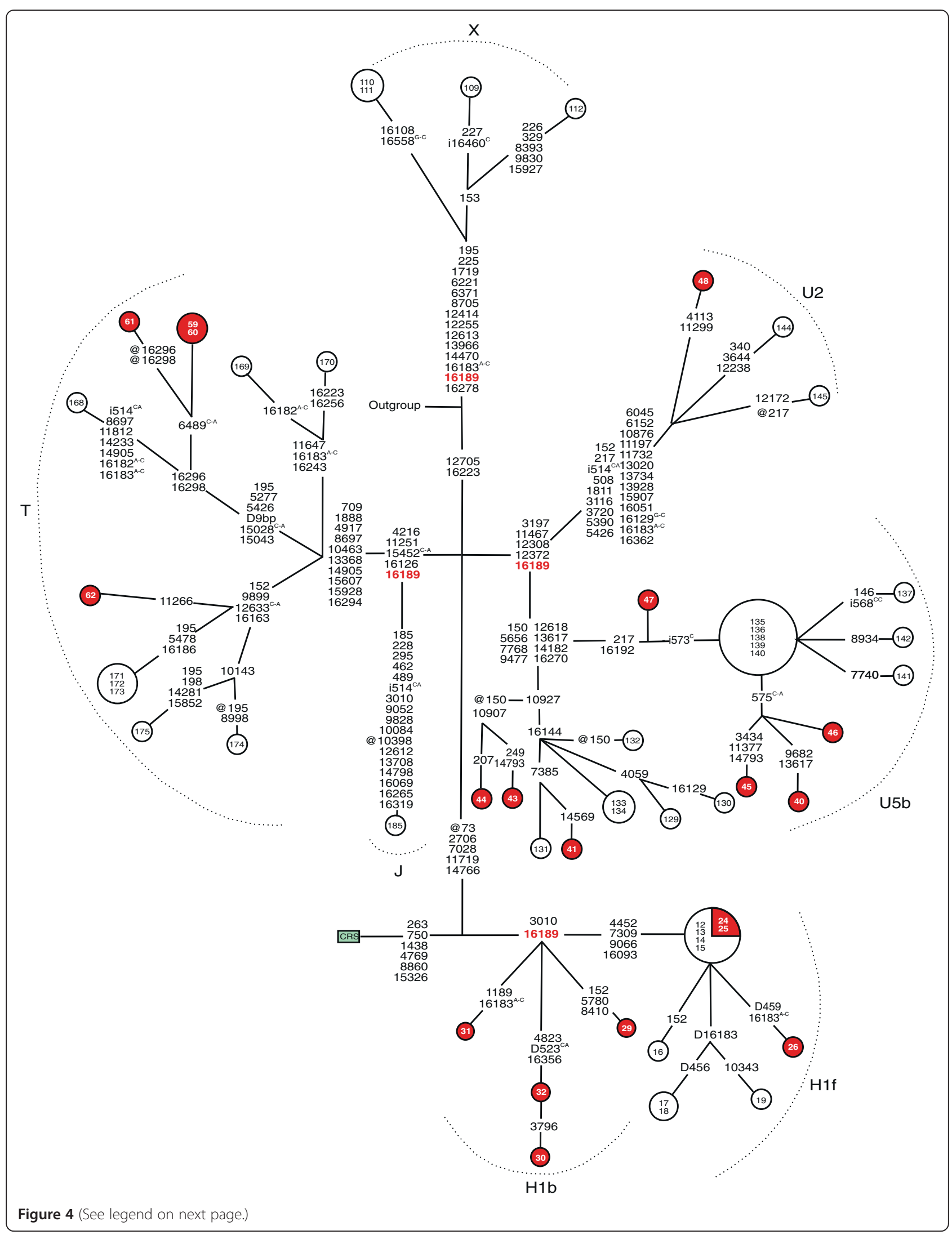


(See figure on previous page.)

Figure 4 Phylogenetic network of mtDNA harbouring $\mathbf{m} .16189 \mathbf{T}>\mathbf{C}$. Red nodes, patients with matrilineal diabetes ( $\mathrm{N}=19$ ); white nodes, population controls $(\mathrm{N}=37)$. Cases are numbered $24-62$, controls numbered as previously published [3]. The fast evolving site m.16519 and the variants in the C-tract between the positions m.303-315 were not included in the network. Outgroup, an African sequence [GenBank:AF346980]; CRS, the revised Cambridge Reference Sequence [GenBank:NC_012920]. Unless marked otherwise, mtDNA variants are transitions. Superscripts indicate transversions, inserted or deleted nucleotides: i=insertion, D=deletion, @=back mutation. D9bp, deletion spanning between the positions $\mathrm{m} .8281$ and $\mathrm{m} .8289$.

Phylogenetic analysis of case and control mtDNA sequences containing m.16189 $\mathrm{T}>\mathrm{C}$ revealed four patients but no controls belonging to subhaplogroup H1b (Figure 4). Subhaplogroup $\mathrm{H} 1$ is defined by m.3010 G > A [48]. Subhaplogroups H1b and H1f both harbour m.3010 G > A and m.16189 T $>$ C, but H1f harbours additional polymorphisms at positions m.4452, m.7309, m.9066, and m.16093. The combination of $\mathrm{m} .3010 \mathrm{G}>\mathrm{A}$ and $\mathrm{m} .16189 \mathrm{~T}>\mathrm{C}$ is also present in the Asian subhaplogroup D4b [28]. Interestingly, an association between type 2 diabetes and m.16189 T $>C$ has been found in Asians [19,20] and subhaplogroup D4b has been linked with a significantly increased risk for type 2 diabetes in Korean men [49]. These findings suggest that $\mathrm{m} .3010 \mathrm{G}>\mathrm{A}$ and $\mathrm{m} .16189 \mathrm{~T}>\mathrm{C}$ occurring in subhaplogroup $\mathrm{H} 1 \mathrm{~b}$ and in subhaplogroup D4b contribute to the risk of diabetes, but the same variants occurring in subhaplogroup H1f do not have such an effect. Our statistical analysis is limited by the small sample size and, furthermore, the results must be regarded as population-spesific. More samples are needed to better understand the link between maternally inherited diabetes and the suggested mildly deleterious mtDNA variants and haplogroups.

\section{Conclusions}

We determined 64 complete mtDNA sequences of Finnish patients with matrilineal diabetes and discovered

Table 3 Number of cytosines in the m.16179-m.16195 region in matrilineal diabetes patients and controls

\begin{tabular}{|c|c|c|c|c|c|}
\hline \multirow{2}{*}{$\begin{array}{l}\text { Cytosines } \\
\text { (N) }\end{array}$} & \multirow[b]{2}{*}{ Sequence } & \multicolumn{2}{|l|}{ DM } & \multicolumn{2}{|c|}{ Controls } \\
\hline & & $(\mathrm{N})$ & $(\%)$ & $(\mathrm{N})$ & (\%) \\
\hline $5^{*}$ & CAAAACCCCCTCCCCAT & 45 & 70.3 & 292 & 72.4 \\
\hline 7 & CAAAACCTCCCCCCCAT & 0 & 0 & 4 & 0.9 \\
\hline 8 & CAAAACCCСССССТCAT & 5 & 7.6 & 27 & 6.6 \\
\hline 10 & CAAAACCCCCCCCCCAT & 11 & 16.9 & 59 & 14.6 \\
\hline 10 & CAAACCCCCCCCCCAT & 0 & 0 & 3 & 0.7 \\
\hline 11 & CAAACCCCCCCCCCCAT & 2 & 3 & 15 & 3.7 \\
\hline 11 & CAAAACCCCCCCCCCCAT & 1 & 1.5 & 0 & 0 \\
\hline 12 & CAACCCCCCCCCCCCAT & 0 & 0 & 3 & 0.7 \\
\hline
\end{tabular}

* The wild-type mtDNA, revised Cambridge Reference Sequence [GenBank: NC_012920] contains 5 consecutive cytosines followed by a thymine and 4 additional cytosines in position m.16184-16193. DM, patients with matrilineal diabetes mellitus. an excess of haplogroup V. Seven possibly or probably damaging nonsynonymous mtDNA variants were found. We also discovered four patients belonging to subhaplogroup $\mathrm{H} 1 \mathrm{~b}$, which harbours m.16189 $\mathrm{T}>\mathrm{C}$ and m.3010 G $>$ A. The same combination exists in subhaplogroup D4b, which has previously been associated with type 2 diabetes in Korean men. The m.16189 $\mathrm{T}>\mathrm{C}$ and m.3010 G>A occuring together without H1f variants create an infavourable combination of mtDNA variants and could predispose to matrilineal diabetes. We conclude that evolutionary recent nonsynonymous mtDNA variants and rare population-specific haplotypes constitute genetic risk factors for maternally inherited diabetes.

Availability of supporting data

The data sets supporting the results of this article are available in the [GenBank] repository, [GenBank:JX171077, GenBank:JX171078, GenBank:JX171079, GenBank:JX171080, GenBank:JX171081, GenBank:JX171082, GenBank:JX171083, GenBank:JX17084, GenBank:JX17085, GenBank:JX17086, GenBank:JX17087, GenBank:JX17088, GenBank:JX17089, GenBank:JX17090, GenBank:JX17091, GenBank:JX17092, GenBank:JX17093, GenBank:JX17094, GenBank:JX17095, GenBank:JX17096, GenBank:JX17097, GenBank:JX17098, GenBank:JX17099, GenBank:JX17100, GenBank:JX17101, GenBank:JX17102, GenBank:JX17103, GenBank:JX17104, GenBank:JX17105, GenBank:JX17106, GenBank:JX17107, GenBank:JX17108, GenBank:JX17109, GenBank:JX17110, GenBank:JX17111, GenBank:JX17112, GenBank:JX17113, GenBank:JX17114, GenBank:JX17115, GenBank:JX17116, GenBank:JX17117, GenBank:JX17118, GenBank:JX17119, GenBank:JX17120, GenBank:JX17121, GenBank:JX17122, GenBank:JX17123, GenBank:JX17124, GenBank:JX17125, GenBank:JX17126, GenBank:JX17127, GenBank:JX17128, GenBank:JX17129, GenBank:JX17130, GenBank:JX17131, GenBank:JX17132, GenBank:JX17133, GenBank:JX17134, GenBank:JX17135, GenBank:JX17136, GenBank:JX17137, GenBank:JX17138, GenBank:JX17139, GenBank:JX17140].

\footnotetext{
Abbreviations

mtDNA: Mitochondrial DNA; ROS: Reactive Oxygen Species; CSGE: Conformation Sensitive Gel Electrophoresis; D-loop: Displacement loop - noncoding mitochondrial DNA control region; SNP: Single Nucleotide Polymorphism; RFLP: Restriction Fragment Lenght Polymorphism.
}

\section{Competing interests}

The authors declare that they have no competing interests. 


\section{Authors' contributions}

HKS: Carried out the conformation sensitive gel electrophoresis, sequencing, mtDNA verified novel substitutions, constructed the phylogenetic trees and wrote the first version of the manuscript. JSM: Reviewed patient registers to select patients with maternally inherited diabetes mellitus, collected and edited the mtDNA sequence data into sequence files, submitted mtDNA sequences, contributed to the study plan, data analysis and the manuscript writing. SF: Contributed to the study plan and data analysis. KM: Collected and selected the patients, planned the study protocol, reviewed the manuscript critically. All authors read and approved the manuscript.

\section{Acknowledgements}

We wish to thank Ms. Pirjo Keränen, Ms. Anja Heikkinen and Ms. Irma Vuoti for their expert technical assistance. We thank Mr. Risto Bloigu for his expert statistical advice. This work was supported by grants from the Academy of Finland (project numbers 107174 and 127764), the Sigrid Juselius Foundation and the Finnish Graduate School for Population Genetics.

\section{Author details}

${ }^{1}$ Institute of Clinical Medicine, Department of Neurology, University of Oulu, P.O. Box 5000, FI-90014, Oulu, Finland. ${ }^{2}$ Clinical Research Center, Oulu University Hospital, University of Oulu, P.O. Box 5000, Fl-90014, Oulu, Finland. ${ }^{3}$ Institute of Clinical Medicine, Department of Clinical Genetics, University of Oulu, P.O. Box 5000, Fl-90014, Oulu, Finland.

Received: 2 April 2012 Accepted: 23 June 2012

Published: 10 July 2012

\section{References}

1. DiMauro S, Schon EA: Mitochondrial respiratory-chain diseases. $N$ Engl J Med 2003, 348:2656-2668.

2. Ylikallio E, Suomalainen A: Mechanisms of mitochondrial diseases. Ann Med 2011, 1:19. online article http://informahealthcare.com/doi/abs/10.3109/ 07853890.2011.598547

3. Finnilä S, Lehtonen MS, Majamaa K: Phylogenetic network of European mtDNA. Am J Hum Genet 2001, 68:1475-1484.

4. Niemi AK, Hervonen A, Hurme M, Karhunen PJ, Jylhä M, Majamaa K: Mitochondrial DNA polymorphisms associated with longevity in a Finnish population. Hum Genet 2003, 112:29-33.

5. Lenaz G, Genova ML: Structural and functional organization of the mitochondrial respiratory chain: a dynamic super-assembly. Int J Biochem Cell Biol 2009, 10:1750-1772.

6. Lenaz G, Mörl M, Florentz C: Mitochondrial tRNA 3' end metabolism and disease. Nucleic Acids Res 2004, 32:5430-5441.

7. Moilanen JS, Majamaa K: Phylogenetic network and physicochemical properties of nonsynonymous mutations in the protein-coding genes of human mitochondrial DNA. Mol Biol Evol 2003, 20:1195-1210.

8. Achilli A, Olivieri A, Pala M, Kashani BH, Carossa V, Perego UA, Gandifi F, Santoro A, Battaglia V, Grugni V, Lancioni H, Sirolla C, Bonfigli AR, Cormio A, Boemi M, Testa I, Semino O, Ceriello A, Spazzafumo L, Gadaleta MN, Marra M, Testa R, Franceschi C, Torroni A: Mitochondrial DNA backgrounds might modulate diabetes complications rather than T2DM as a whole. PLOS One 2011, 6:e21029.

9. Moilanen JS, Finnilä S, Majamaa K: Lineage-specific selection in human mtDNA: lack of polymorphisms in a segment of MTND5 gene in haplogroup J. Mol Biol Evol 2003, 20:2132-2142.

10. Elson JL, Turnbull DM, Howell N: Comparative genomics and the evolution of human mitochondrial DNA: assessing the effects of selection. Am J Hum Genet 2004, 74:229-238.

11. Alcolado JC, Laji K, Gill-Randall R: Maternal transmission of diabetes. Diabet Med 2002, 19:89-98.

12. Van den Ouweland JM, Lemkes HH, Trembath RC, Ross R, Velho G, Cohen D, Froguel $P$, Maassen JA: Maternally inherited diabetes and deafness is a distinct subtype of diabetes and associates with a single point mutation in the mitochondrial tRNA(Leu(UUR)) gene. Diabetes 1994, 43:746-751.

13. Majamaa K, Moilanen JS, Uimonen S, Remes AM, Salmela PI, Kärppä M, Majamaa-Voltti KA, Rusanen H, Sorri M, Peuhkurinen KJ, Hassinen IE: Epidemiology of $A 3243 G$, the mutation for mitochondrial encephalomyopathy, lactic acidosis, and strokelike episodes: prevalence of the mutation in an adult population. Am J Hum Genet 1998, 63:447-454

14. Liou CW, Lin TK, Chen JB, Tiao MM, Weng SW, Chen SD, Chuang YC, Wang PW: Association between a common mitochondrial DNA D-loop polycytocine variant and alteration of mitochondrial copy number in human peripheral blood cells. J Med Genet 2010, 47:723-728.

15. Parker E, Phillips DI, Cockington RA, Cull C, Poulton J: A common mitochondrial DNA variant is associated with thinness in mothers and their 20-yr-old offspring. Am J Physiol Endocrinol Metab 2005, 6:1110-1114.

16. Casteels K, Ong K, Phillips D, Bendall H, Pembrey M: Mitochondrial 16189 variant, thinness at birth, and type-2 diabetes. Lancet 1999, 353:1499-1500.

17. Liou CW, Lin TK, Huei Weng H, Lee CF, Chen TL, Wei YH, Chen SD, Chuang YC, Weng SW, Wang PW: A common mitochondrial DNA variant and increased body mass index as associated factors for development of type 2 diabetes: Additive effects of genetic and environmental factors. J Clin Endocrinol Metab 2007, 92:235-239.

18. Poulton J, Luan J, Macaulay V, Hennings S, Mitchell J, Wareham NJ: Type 2 diabetes is associated with a common mitochondrial variant: evidence from a population-based case-control study. Hum Mol Genet 2002, 11:1581-1583.

19. Park KS, Chan JC, Chuang L-M, Suzuki S, Araki E, Nanjo K, Ji L, Ng M, Nishi M, Furuta H, Shirotani T, Ahn BY, Chung SS, Min H-K, Lee SW, Kim JH, Cho YM, Lee HK: A mitochondrial variant at position 16189 is associated with type 2 diabetes mellitus in Asians. Diabetologia 2008, 51:602-608.

20. Weng SW, Liou CW, Lin TK, Wei YH, Lee CF, Eng HL, Chen SD, Liu RT, Chen JF, Chen IY, Chen MH, Wang PW: Association of mitochondrial deoxyribonucleic acid 16189 variant ( $\mathrm{T}>\mathrm{C}$ transition) with metabolic syndrome in Chinese adults. J Clin Endocrinol Metab 2005, 90:5037-5040.

21. Van Esch A, Steyerberg EW, Berger MY, Offringa M, Derksen-Lubsen G, Habbema JDF: Family history and recurrence of febrile seizures. Arch Dis Child 1994, 70:395-399.

22. Meinilä M, Finnilä S, Majamaa K: Evidence for mtDNA admixture between the Finns and the Saami. Hum Hered 2001, 52:160-170.

23. Torroni A, Huoponen K, Francalacci P, Petrozzi M, Morelli L, Scozzari R, Obinu D, Savontaus ML, Wallace DC: Classification of European mtDNA's from an analysis of three European populations. Genetics 1996, 144:1835-1850.

24. Finnilä S, Hassinen IE, Ala-Kokko L, Majamaa K: Phylogenetic network of the mtDNA haplogroup $U$ in Northern Finland based on sequence analysis of the complete coding region by conformation-sensitive ge electrophoresis. Am J Hum Genet 2000, 66:1017-1026.

25. Körkkö J, Annunen S, Pihlajamaa T, Prockop DJ, Ala-Kokko L: Conformation sensitive gel electrophoresis for simple and accurate detection of mutations: comparison with denaturing gradient gel electrophoresis and nucleotide sequencing. Proc Natl Acad Sci USA 1998, 95:1681-1685.

26. Werle E, Schneider C, Renner M, Völker M, Fiehn W: Convenient single-step, one tube purification of PCR products for direct sequencing. Nucleic Acids Res 1994, 22:4354-4355.

27. Andrews RM, Kubacka I, Chinnery PF, Lightowlers RN, Turnbull DM, Howell N: Reanalysis and revision of the Cambridge reference sequence for human mitochondrial DNA. Nat Genet 1999, 23:147.

28. Tanaka M, Cabrera VM, Gonzalez AM, Larruga JM, Takeyasu T, Fuku N, Guo LJ Hirose R, Fujita Y, Kurata M, Shinoda K, Umetsu K, Yamada Y, Oshida Y, Sato Y, Hattori N, Mizuno Y, Arai Y, Hirose N, Ohta S, Ogawa O, Tanaka Y, Kawamori R, Shamoto-Nagai M, Maruyama W, Shimokata H, Suzuki R, Shimodaira H: Mitochondrial genome variation in eastern Asia and the peopling of Japan. Genome Res 2004, 14(10A):1832-1850.

29. Ingman M, Gyllensten U: mtDB: Human Mitochondrial Genome Database, a resource for population genetics and medical sciences. Nucleic Acids Res 2006, 34:D749-D751.

30. Ruiz-Pesini E, Lott MT, Procaccio V, Poole JC, Brandon MC, Mishmar D, Yi C, Kreuziger J, Baldi P, Wallace DC: An enhanced MITOMAP with a global mtDNA mutational phylogeny. Nucleic Acids Res 2007, 35:D823-D828.

31. Pütz J, Dupuis B, Sissler M, Florentz C: Mamit-tRNA, a database of mammalian mitochondrial tRNA primary and secondary structures. RNA 2007, 13:1184-1190.

32. Adzhubei IA, Schmidt S, Peshkin L, Ramensky VE, Gerasimova A, Bork P, Kondrashov AS, Sunyaev SR: A method and server for predicting damaging missense mutations. Nat Methods 2010, 7:248-249. 
33. Rost B, Yachdav G, Liu J: The PredictProtein Server. Nucleic Acids Res 2003, 32(Web Server issue):W321-W326.

34. Bandelt HJ, Forster P, Sykes BC, Richards MB: Mitochondrial portraits of human populations using median networks. Genetics 1995, 141:743-753.

35. Tambets K, Rootsi S, Kivisild T, Help H, Serk P, Loogväli EL, Tolk HV, Reidla M, Metspalu E, Pliss L, Balanovsky O, Pshenichnov A, Balanovska E, Gubina M, Zhadanov S, Osipova L, Damba L, Voevoda M, Kutuev I, Bermisheva M, Khusnutdinova E, Gusar V, Grechanina E, Parik J, Pennarun E, Richard C, Chaventre A, Moisan JP, Barac L, Pericic M, Rudan P, Terzic R, Mikerezi I, Krumina A, Baumanis V, Koziel S, Rickards O, De Stefano GS, Anagnou N, Pappa Kl, Michalodimitrakis E, Ferak V, Furedi S, Komel R, Beckman L, Villems R: The western and eastern roots of the Saami-the story of genetic "outliers" told by mitochondrial DNA and Y choromosomes. Am J Hum Genet 2004, 74:661-682.

36. Ross AB, Johansson A, Ingman M, Gyllensten U: Lifestyle, genetics and disease in Sami. Croat Med J 2006, 47:553-565.

37. Palanichamy MG, Sun C, Agrawal S, Bandelt HJ, Kong QP, Khan F, Wang CY, Chaudhuri TK, Palla V, Zhang YP: Phylogeny of mitochondrial DNA macrohaplogroup $\mathrm{N}$ in India, based on complete sequencing: implications for the peopling of South Asia. Am J Hum Genet 2004 75:966-978.

38. Kirches E, Winkler K, Vielhaber S, Michael M, Warich-Kirches M, von Bossanyi P, Plate I, Kunz WS, Szibor R, Feistner H, Dietzmann K: Mitochondrial tRNA (Cys) mutation A5823G in a patient with motor neuron disease and temporal lobe epilepsy. Pathobiology 1999, 67:214-218.

39. Levinger $L$, Mörl M, Florentz C: Mitochondrial tRNA 3' end metabolism and disease. Nucleic Acids Res 2004, 32:5430-5441.

40. McFarland R, Elson JL, Taylor RW, Howell N, Turnbull DM: Assigning pathogenicity to mitochondrial tRNA mutations: when 'definitely maybe' is not good enough. Trends Genet 2004, 20:591-596.

41. Lehtonen MS, Moilanen JS, Majamaa K: Increased variation in mtDNA in patients with familial sensorineural hearing impairment. Hum Genet 2003, 113:220-227.

42. Khusnutdinova E, Gilyazova I, Ruiz-Pesini E, Derbeneva O, Khusainova R, Khidiyatova I, Magzhanov R, Wallace DC: A mitochondrial etiology of neurodegenerative diseases: evidence from Parkinson's disease. Ann NY Acad Sci 2008, 1148:1-20.

43. Petros JA, Baumann AK, Ruiz-Pesini E, Amin MB, Sun CQ, Hall J, Lim S, Issa MM, Flanders WD, Hosseini SH, Marshall FF, Wallace DC: mtDNA mutations increase tumorigenicity in prostate cancer. Proc Natl Acad Sci USA 2005, 102:719-724.

44. Varlamov DA, Kudin AP, Vielhaber S, Schröder R, Sassen R, Becker A, Kunz D, Haug K, Rebstock J, Heils A, Elger CE, Kunz WS: Metabolic consequences of a novel missense mutation of the mtDNA CO I gene. Hum Mol Genet 2002, 11:1797-1805.

45. Herrnstadt C, Elson JL, Fahy E, Preston G, Turnbull DM, Anderson C, Ghosh SS, Olefsky JM, Beal MF, Davis RE, Howell N: Reduced-median-network analysis of complete mitochondrial DNA coding-region sequences for the major African, Asian, and European haplogroups. Am J Hum Genet 2002, 70:1152-1171.

46. Das S, Bennett AJ, Sovio U, Ruokonen A, Martikainen H, Pouta A, Hartikainen A-L, Franks S, Elliott P, Poulton J, Järvelin M-R, McCarthy MI: Detailed analysis of variation at and around mitochondrial position 16189 in a large Finnish cohort reveals no significant associations with early growth or metabolic phenotypes at age 31 years. J Clin Endocrinol Metab 2007, 92:3219-3223.

47. Mohlke KL, Jackson AU, Scott L, Peck EC, Suh YD, Chines PS, Watanabe RM, Buchanan TA, Conneely KN, Erdos MR, Narisu N, Enloe S, Valle TT, Tuomilehto J, Bergman RN, Boehnke M, Collins FS: Mitochondrial polymorphisms and susceptibility to type 2 diabetes -related traits in Finns. Hum Genet 2005, 118:245-254.

48. Loogväli E-L, Roostalu U, Malyarchuk BA, Derenko MV, Kivisild T, Metspalu E, Tambets K, Reidla M, Tolk H-V, Parik J, Pennarun E, Laos S, Lunkina A, Golubenko M, Barác L, Pericic M, Balanovsky OP, Gusar V, Khusnitdinova EK, Stepanov V, Puzyrev V, Rudan P, Balanovska EV, Grechanina E, Richard C, Moisan J-P, Chaventré A, Anagnou NP, Pappa KI, Michalodimitrakis EN, Claustres M, Gölge M, Mikerezi I, Usanga E, Villems R: Disuniting Uniformity: A pied cladistic canvas of mtDNA haplogroup $\mathrm{H}$ in Eurasia. Mol Biol Evol 2004, 21:2012-2021.
49. Nishigaki Y, Fuku N, Tanaka M: Mitochondrial haplogroups associated with lifestyle-related diseases and longevity in the Japanese population. Geriatr Gerontol Int 2010, 10:S221-S235.

doi:10.1186/1756-0500-5-350

Cite this article as: Soini et al:: Mitochondrial DNA sequence variation in Finnish patients with matrilineal diabetes mellitus. BMC Research Notes 2012 5:350.

\section{Submit your next manuscript to BioMed Central and take full advantage of:}

- Convenient online submission

- Thorough peer review

- No space constraints or color figure charges

- Immediate publication on acceptance

- Inclusion in PubMed, CAS, Scopus and Google Scholar

- Research which is freely available for redistribution

Submit your manuscript at www.biomedcentral.com/submit
C BioMed Central 